\title{
A violência entre a inclusão e a exclusão social
}

\author{
MARIASTELA GROSSI PORTO
}

\begin{abstract}
RESUMO: O texto objetiva pensar a existência de novos sentidos/significados da violência no Brasil, argumentando que seu surgimento articula-se a transformações na natureza da sociedade brasileira, as quais, por sua vez, inserem-se no contexto de transformações mais abrangentes, combinando processos de globalização e fragmentação. A reflexão articula, igualmente, novos ângulos de análise que conduzem a pensar a violência também através de uma relação entre exclusão/inclusão, apreendidas não como formas excludentes e dicotômicas mas como categorias integrantes de uma mesma dinâmica, na qual atores sociais podem vivenciar alternadamente formas de inclusão/ exclusão decorrentes de processos sociais fragmentados, diferenciados e plurais.
\end{abstract}

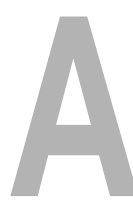

exclusão social tem sido uma categoria importante e presente nas análises que buscam relacionar violência e direitos civis. Enfatizase o fato de que os excluídos dos direitos tornam-se alvos, ou atores, mais imediatos da violência. Sem negar a importância dos vínculos que, de um modo geral, permitem associar tais fenômenos, propomonos a refletir, igualmente, sobre aspectos, manifestações e contextos de violência cujos protagonistas encontram-se, também, em camadas ou grupos sociais normalmente considerados como incluídos. Ou, seria talvez mais pertinente pensar contextos e situações nos quais inclusão e exclusão, concebidas como categorias que perpassam dimensões econômicas tanto quanto sociais e culturais de um dado espaço social, podem se entrecruzar no decurso de um mesmo sistema de ação de um ator social, individual ou coletivo.
UNITERMOS: violência urbana, inclusão social, exclusão social, mudança social.

Texto apresentado no VIII Congresso da Sociedade Brasileira de Sociologia, Brasília, agosto de 1997.

Professora do Departamento de Sociologia do ICS - UnB 
Esta abordagem se justifica pela impossibilidade de circunscrever a análise do fenômeno a qualquer categoria de caráter unificador, mas, também, pela necessidade de explorar novos ângulos desta análise que conduzam a refletir a violência através de uma relação dinâmica entre inclusão e exclusão, apreendidas não mais como formas dicotômicas e excludentes mas, ao contrário, como categorias integrantes de uma mesma dinâmica, na qual atores sociais podem vivenciar alternadamente formas de inclusão/exclusão decorrentes de processos sociais fragmentados, diferenciados e plurais.

O texto se divide em duas partes. Na primeira, busca-se analisar mudanças na natureza do espaço social brasileiro, relacionando-as ao movimento mais geral da inserção da sociedade brasileira em processos de transformação que ultrapassam a sociedade nacional. Na segunda, objetiva-se refletir sobre como os novos sentidos da violência articulam-se às transformações ocorridas.

\section{Violência: o contexto das mudanças}

As recentes transformações pelas quais tem passado a sociedade brasileira podem ser analisadas como inseridas no contexto de transformações maiores, que têm como palco o contexto mundial e que combinam em formas múltiplas processos de globalização e fragmentação. As mudanças daí decorrentes transformam de forma mais ou menos radical a natureza da trama social, conduzindo a que reflexões voltadas a realidades nacionais tenham que levar em conta sua inserção no mundo globalizado.

Para o tema da violência, esta abordagem tem a vantagem de ampliar o quadro conceitual e o espaço empírico a partir dos quais a violência pode ser analisada. Ainda que o objetivo da análise seja a compreensão de processos que têm como locus a sociedade brasileira, percebe-se a insuficiência dos contornos do Estado-Nação enquanto enquadramento para a reflexão. Isso porque as mudanças que atravessam o conjunto da sociedade brasileira desenvolvem-se no contexto de transformações que são mundiais e inserem reflexões de caráter nacional no movimento mais geral destas transformações, pensadas a um só tempo enquanto propulsoras e resultantes do processo de globalização. Convém ressaltar que não está em questão qualquer hipótese sobre a superação do Estado Nacional. Mesmo que algumas das temáticas presentes nas agendas governamentais de sociedades tão distintas como a do Brasil e de países europeus, por exemplo, apresentem inúmeras semelhanças e pontos de contatos, a natureza das respostas encontradas está circunscrita a especicificidades e singularidades nacionais, irredutíveis a processos globais.

Assim, se por um lado, a globalização assume o estatuto de uma categoria articuladora do pensamento e da análise a indicar a abrangência e a radicalidade das mudanças, por outro, não implica a identificação entre globalização e homogeneização. Se é pertinente supor que transformações, sobretudo no nível tecnocientífico, atinjam o âmbito planetário, as formas através das quais este movimento se realiza encontram, no entanto, configura- 
ções sociais as mais diferenciadas, levando a definições e redefinições do espaço sociocultural igualmente diferenciadas, em um movimento no qual globalização, enquanto tendência, e fragmentação/diversificação, enquanto espaço empírico de manifestação/realização da tendência, podem constituir de fato um processo único. Movimento que ressalta a pertinência de análises que contemplem as relações entre o geral e o particular na análise sociológica.

É a partir desses parâmetros de interpretação que se está pretendendo compreender a inserção da sociedade brasileira na contemporaneidade de um mundo globalizado, e é igualmente este o contexto em que se espera poder refletir sobre o fenômeno da violência no Brasil.

O objetivo é ampliar o conhecimento sobre a natureza do social em que manifestações de violência têm lugar, lembrando, em primeiro lugar, que são flexíveis e mutantes os contornos do que uma sociedade, segundo determinadas épocas e determinados ambientes socioculturais, nomeia como violência. E, em segundo lugar, ressaltando o fato de que as possíveis relações entre manifestações de fenômenos de violência e processos de globalização jamais se dão a perceber de forma imediata e direta. Apenas são passíveis de compreensão se apreendidos através de múltiplos mecanismos de mediação, que se estabelecem entre ambos os fenômenos.

Com relação ao primeiro aspecto, esta análise vai no sentido de perceber que estaria ocorrendo no Brasil de hoje uma ressignificação da violência. A dificuldade por vezes ressentida, ao se definir violência, decorre do fato de que, não se tratando de um conceito sociológico, mas de uma categoria empírica de manifestação do social, sua compreensão é dependente dos arranjos societários de que emerge. Daí a recorrência das análises onde a violência é caracterizada como algo ambíguo, relativo.

Michaud assinala que tais ambigüidade e relatividade da noção de violência necessitam ser investigadas através de uma análise que se interrogue sobre o que ele considera como "a violência da violência, isto é, as condições a partir das quais a violência é apreendida como tal"'(Michaud, 1978, p. 23). Análise que permita emergir o uso político que se faz da categoria e dos discursos sobre o fenômeno segundo contextos sociais distintos. Para este autor "a noção de violência é... por princípio ambígua, sua significação é estabelecida por procedimentos políticos segundo o grupo que, em um dado momento, tem o poder de rotulá-la contra outros (grupos)... pode aparecer e desaparecer segundo quem fala. Concretamente, isto significa que ela pode continuar sendo o que é ainda que nem sempre seja reconhecida ou desconhecida como tal. As multidões de torcedores de equipes esportivas não cometem violências mais 'depredações em função da má educação do público esportivo'. As brigas que se seguem aos bailes de sábado à noite tornaram-se violência, ao passo que durante muito tempo elas eram apenas parte do folclore do alcoolismo nacional. De maneira menos benevolente, um opositor político pode ser, segundo o caso, um criminoso, sujeito ao direito comum, um terrorista, um dissidente, um contestador ou um esquizofrênico; não se trata simples- 
mente de uma questão de palavras: pode-se aperceber disso a partir do tipo de 'tratamento' a que será submetido" (Michaud, 1978, p. 92).

No próprio conjunto de exemplos mencionados pelo autor, constata-se o deslocamento de sentido: hoje, é na condição de violência que são apreendidos os distúrbios provocados pelas torcidas esportivas.

Deslocamento semelhante pode ser detectado no contexto da realidade brasileira. Quando se reflete sobre crimes e violências de natureza sexual, as situações com as quais se confronta o analista do social aproximam-se, em certo sentido, do exemplo acima. Há não mais de poucas décadas, estupro ou espancamento de mulheres eram fenômenos tratados na esfera privada, não nomeados como violência. A própria criação de delegacias da mulher e a criminalização de atos de violência contra a mulher sinalizam para novos sentidos do que se considera violência, o que reflete um outro estatuto da condição feminina. Apontam, também, para uma maior igualdade entre os sexos, na medida em que a mulher se constitui enquanto portadora de direitos.

É ainda este mesmo deslocamento de sentido em relação ao que se assume como pertinente às esferas do público e do privado o que permite reconhecer crianças e adolescentes como sujeitos de direito, em defesa dos quais se pode questionar legalmente o arbítrio do poder familiar.

Mutatis mutandis, o argumento também parece útil para que se reflita sobre a condição de minorias sexuais, cujas conquistas em direção ao reconhecimento das diferenças têm viabilizado o deslocamento da questão de um patamar físico-biológico, no qual diferenças sexuais eram assumidas de forma medicalizada (como doença) para um contexto em que a opção sexual passa a ser postulada como direito.

Mudanças na apreensão da noção de violência, como as acima mencionadas, sinalizam algo novo. Não se está pretendendo que formas de preconceito, e manifestações de violência, que por vezes expressam-nas, tenham desaparecido da sociedade brasileira mas que tais mudanças estejam evidenciando transformações na natureza do social; transformações que a análise sociológica terá que se esforçar para compreender. É, pois, utilizando-as como suporte que se pretende desenvolver uma argumentação que avança a hipótese orientadora dessa reflexão. Hipótese que aponta duas direções para o raciocínio.

A primeira, apropriando-se, talvez de forma pouco ortodoxa, da tese defendida por Elias (1990), na análise do processo civilizatório, supõe a sociedade brasileira transpondo novos patamares nesse/desse processo, o que a levaria a uma reconceitualização da violência, de modo a incluir e a nomear como violência acontecimentos que passavam anteriormente por práticas costumeiras de regulamentação das relações sociais. Práticas fundadas em uma rígida hierarquização do social que instituía a desigualdade como processo legítimo, por assim dizer, de estruturação do social. Práticas nas quais a relativa indiferenciação público/privado propiciava, nos dizeres de Freire, o desenvolvimento de uma sociedade "(defendida) menos pela ação oficial do que pelo braço e pela espada do particular” (Freire, 1963, p. 69). 
A mudança, que parece pertinente assinalar, refere-se fundamentalmente à propensão a se nomear e a se reconhecer a violência, sendo concomitante a essa realidade a recusa em se atribuir legitimidade à violência enquanto forma de estruturação e de regulação do social.

As novas possibilidades de organização da sociedade civil têm propiciado indícios que confirmariam a pertinência dessa hipótese, ao sinalizar como crise e até mesmo como barbárie, demonstrações de violência que foram, tantas vezes, assumidas no passado como traços culturais. Nesse sentido, pode-se afirmar que hoje a sociedade brasileira percebe a violência de uma forma diversa daquelas que conformavam o social dos tempos da casa-grande e senzala.

Não parece demais ressaltar: não se está fazendo nenhuma afirmação em termos de uma avaliação quantitativa do fenômeno. Não está em questão, nesta argumentação, se trata-se de mais ou menos violência mas do fato de que seu significado social parece hoje distinto do que foi anteriormente. Fato que também se alia à percepção de que tal transformação parece simultânea ao aflorar de uma sensibilidade coletiva - por mais imprecisa que tal noção possa ser - mais aguçada, advogando como inaceitável a estruturação do social pela violência.

Considere-se a seguir a segunda direção para a qual se encaminha a hipótese. Mesmo sem presumir relações mecânicas de causa e efeito, não convém, ainda assim, descartar, a priori, níveis de interdependência entre reconceitualização da violência, nos termos acima estabelecidos, e a maior visibilidade do fenômeno, potencializada com o processo de redemocratização.

Enquanto produto de demandas e conquistas da sociedade civil, o retorno à democracia, ou de práticas sociais institucionalizadas, articula-se a um movimento amplo de reivindicação do estado de direito enquanto condição de realização da igualdade na cidadania. Isso significa, também no nível jurídico, a reivindicação de procedimentos menos particularistas, mais conforme ao apelo por normas mais universalistas, características da modernidade. Mesmo que se admita que estes são processos ainda incipientes, seu significado para a reconstrução institucional não parece desprezível.

Para os objetivos da análise que ora se realiza, por exemplo, parece pertinente postular que a maior visibilidade do fenômeno da violência no contexto da redemocratização, bem como sua rejeição decorrente de um refinamento do que se está chamando sensibilidade coletiva, articulam-se, igualmente, a uma postura muito mais enérgica da sociedade face ao fenômeno da impunidade.

Ainda que correndo o risco de partilhar um certo viés evolucionista, perceptível aqui e ali na argumentação de Elias, arriscaria a afirmação de que a sociedade brasileira conquistou patamares de civilidade que a tornam intransigente face à violência, aí compreendido o que aqui se está considerando como sua redefinição, e à impunidade para os atos e atores da violência. $\mathrm{O}$ apelo por punição e por justiça em relação à violência policial, que os meios de comunicação de massa tornam muito mais visível na vigência de práticas democráticas, é um exemplo do que se está afirmando. Para Michaud, muito provavelmente a unidade do social, que impede a violência de aparecer, re- 
pousa sobre processos rígidos de dominação: "não é sem significação que a noção de violência tenha aparecido e continue a aparecer preferencialmente em sociedades mais democráticas do que totalitárias e que duvidem delas mesmas: o terror produz ao contrário todas as aparências de calma"(Michaud, 1978, p. 101). Para este autor, ainda que o mundo moderno se pense mais violento do que no passado, tal comparação é desprovida de sentido: "o que era brutalidade, rudeza, ordem normal da miséria ou da dominação tornou-se insuportável"(Michaud, 1978, p. 101).

Que relações poderiam ser pensadas entre processos de globalização, este novo na natureza do social no Brasil e o fenômeno da violência?

Haveria uma primeira relação, relevante para a análise que se está desenvolvendo, que aqui apenas se esboça. Esta relação vincula-se ao fato de que a sociedade brasileira não está alheia às transformações científicas e tecnológicas que se processam em nível mundial. De que modo se materializa esta participação é algo que foge aos objetivos do texto, já que o tratamento de tal questão exigiria análises empíricas específicas. Vale a pena, no entanto, refletir sobre prováveis repercussões das transformações em determinadas dimensões da vida social como, por exemplo, o que vem ocorrendo em termos dos processos de informação. Sob este aspecto, poder-se-ia dizer que o Brasil mergulhou, de forma mais aguda e radical do que países ditos avançados, na era das novas tecnologias. A um ponto, que não parece exagero dizer que a radicalidade e a abrangência das transformações seriam elas mesmas uma forma de violência, na medida em que rompem, redefinem, deslocam ou superam o tradicional e os processos de organização do social por ele informados, afetando a sociedade em múltiplos aspectos e em diferentes esferas: da econômica à social, política e cultural. Esse consumo tecnológico, em que mergulhou a sociedade brasileira, mereceria uma análise em profundidade, na medida em que se vem revelando como componente importante de traços culturais típicos.

Assim, mudanças tecnológicas, decorrentes dos avanços da ciência, alteram profundamente a relação física e cultural com o espaço. Por exemplo, o Brasil participa cada vez mais fortemente da chamada cultura do shopping center, espaço tecnologicamente organizado e controlado, inclusive no que diz respeito à segurança e aos processos de sociabilidade em curso nos espaços urbanos. Tais mudanças atingem igualmente a dimensão espaço-temporal, em proporções impensadas há alguns poucos anos.

Da mesma forma, novos processos de produção do conhecimento revolucionam os procedimentos de difusão da informação. Nesta esfera, podese, talvez, falar da ‘criação' de um mundo virtual que convive em graus diferenciados de tensão/integração com o mundo real, transformando de modo radical o sentido do que venha a ser experiência. Os meios eletrônicos, ao mesmo tempo que possibilitam a quase simultaneidade entre acontecimento e informação (o mundo é aqui e agora), 'poupam’ os indivíduos, intermediando vários de seus contatos com o mundo. O virtual 'constrói o real'. Pode-se, por exemplo, praticar sexo seguro, porque virtual, viajar no espaço interplanetário ou experimen- 
tar os horrores da guerra da cadeira do computador ou de um jogo eletrônico. $\mathrm{O}$ outro lado desta mesma moeda transforma o real em espetáculo, produzido pelos meios de massa. É o que ocorre, por exemplo, com o fenômeno da violência, transformado em produto, com amplo poder de venda no mercado de informação, e em objeto de consumo, fazendo com que a 'realidade' da violência passe a fazer parte do dia-a-dia, mesmo daqueles que nunca a confrontaram diretamente enquanto experiência de um processo vivido. A violência passa a ser consumida num movimento dinâmico em que o consumo participa também do processo de sua produção, ainda que como representação. Também como representação, multiplicam-se as categorias de percepção da violência.

Essa propensão ao consumo tecnológico, temática que se pretende poder aprofundar em uma próxima reflexão, articula-se com pertinência ao tema proposto nesse texto, na medida em que participa dos processos de ressignificação social da violência como parte das transformações que se processam na natureza da sociedade no Brasil.

A segunda vertente de reflexão decorre de mudanças que se vêm efetivando sobretudo no mundo do trabalho e cuja direção tem apontado para sua superação enquanto componente hegemônico de organização do social e de estruturação das relações sociais. Em um mundo 'regido' pelo trabalho, as classes sociais podiam, em alguma medida, ser pensadas como categorias 'unificadoras' do social. Que isto seja como eixo organizador de interesses (materiais e ideais, segundo a terminologia weberiana), que seja enquanto fator de estruturação de um campo de lutas e, mais ainda, como espaço construtor de identidades, referidas, na maioria das vezes, a posições nas relações de trabalho.

As mudanças tecnológicas, ao incidirem diretamente sobre o mundo do trabalho, deslocando seu caráter de centralidade enquanto organizador de um ambiente sociocultural, transformam a natureza desse social e afetam igualmente o trabalho em suas dimensões simbólica, ideológica e valorativa, dimensões fundamentais, cada uma delas, na definição de condutas e estilos de vida. Enquanto valor, o trabalho era responsável, não tanto pela unidade do social, mas por sua representação como algo unificado. Atualmente, as transformações desse universo do trabalho, e o deslocamento de valores nele centrados, evidenciam o surgimento de um social atomizado, fragmentado, carente de pontos fixos de referência. Os indivíduos e os grupos sociais não mais reconhecem valores ou normas coletivos, ou não mais se reconhecem nesses valores, o que propicia diferentes arranjos societários, articulados ao surgimento de novos atores e ao deslocamento e/ou redefinição de atores tradicionais. Contexto no qual a referência ao social como algo fragmentado, diferenciado e plural parece adquirir pertinência. Dois aspectos merecem ser ressaltados: a pluralidade valorativa, potencializada nestas e por estas mudanças, e sua relação com as ressignificações da violência.

Refletindo sobre a perspectiva durkheimiana da análise sociológica, Michaud (1978) chama a atenção para a preocupação de Durkheim em isolar os fatos sociais de suas manifestações individuais recorrendo, para tal, à delimitação das formas cristalizadas de vida, que são as regras morais e 
jurídicas e os ditos populares constitutivos de pontos de referência para a ação - idênticos e constantes - permitindo a objetivação do social. Recorda, também, Michaud que o próprio Durkheim reconhece, ainda que em pé de página, a ocorrência de circunstâncias nas quais não haveria correspondência entre a forma cristalizada e a dinâmica social. Para Michaud, "essa eventualidade é, de maneira geral, a possibilidade de não mais se encontrar pontos fixos para objetivar um fato social, ou que os pontos fixos sejam variáveis (expressão contraditória, do próprio Durkheim, que convém seja assumida ao pé da letra: uma pluralidade conflitual de pontos fixos que possuem, igualmente, pretensão de validade). Trata-se da eventualidade de que, com relação a certos fenômenos, haja uma pluralidade de maneiras de percebê-los. Ora, é exatamente isto o que ocorre com relação à violência.... Enquanto existem pontos fixos, fruto do consenso cultural ou da imposição pela força, a violência não pode aparecer enquanto tal: os dominantes a exercem, os dominados sofrem-na, mas ela não pode ser dita.... Quando cai por terra a inquestionabilidade dos pontos fixos, abre-se o espaço, ainda que restrito, no qual os discursos podem dizer a violência - entretanto, eles serão necessariamente conflituais uma vez que os pontos fixos são, a partir daí, diversos e variáveis em relação a eles mesmos" (Michaud, 1978, p. 98).

Assim, que, em uma dada sociedade, a violência possa ser identificada de forma múltipla e diferenciada é, para Michaud, decorrência da inexistência de pontos fixos para a objetivação do social. Fenômeno que é também abordado de forma contundente na análise da modernidade elaborada por Max Weber, em termos do paradoxo de valores e da guerra dos deuses (Weber, 1968).

Na perspectiva que aqui se está considerando, e tendo como referência a sociedade brasileira, as transformações que se vêm analisando, sobretudo o que se está chamando sua inserção na modernidade globalizada e a reconstrução dos processos de democratização, são potencializadoras dessa fragmentação valorativa, configurando um processo de dissolução de regras e normas que unificariam o olhar sobre o social.

Estas considerações conduzem à segunda parte do texto em que se pretende refletir, à luz das reflexões desenvolvidas, sobre os sentidos ou significações da violência.

\section{A violência e seus novos sentidos}

Pela argumentação até aqui desenvolvida, estes sentidos não podem ser analisados independentemente do campo social em que se inserem. Se muda a natureza do social, mudam, igualmente, as formas de manifestação da violência e de suas significações. Nesse social, desprovido de categorias e pontos fixos de referências, passível de múltiplos arranjos societários, uma conseqüência possível é a explosão de múltiplas lógicas de ação e de organização e reorganização do espaço social. Lógicas que lançam mão de recursos diferenciados de atuação, entre os quais figura (ou pode figurar) o recurso à 
violência. Violência que vem se caracterizando como difusa e autonomizada face a possíveis sentidos originários. Violência sem objeto, despolitizada, instrumental ou instrumentalizada.

Se a violência não é fato recente, o que significa que sua presença implica continuidades, o que aqui se está, entretanto, ressaltando é o novo que caracteriza essa violência. Uma novidade cujas manifestações se constroem em simultaneidade com as novas configurações do social. Ou seja, a violência contemporânea possui contornos que a distinguem de suas formas tradicionais de manifestação. Convive com estas, mas também contribui para sua destruição, deslocamento e redefinição. Tais contornos vinculam-se a duas ordens de fatores. Em primeiro lugar, à questão dos valores. Neste aspecto, fragmentação sociocultural, ausência de uma representação unificada do social, ausência de pontos fixos de referência norteadores de conduta, são expressões de uma fragmentação valorativa, com repercussões, por exemplo, nos processos de construções identitárias. Em seguida, ao modo como a violência, enquanto manifestação das mudanças do mundo contemporâneo, estaria relacionada à questão da legitimidade, das formas como ela é percebida e do conteúdo mesmo da noção de legitimidade.

Com relação a este último fator mencionado, a violência política, por exemplo, característica das décadas 60 e 70, buscava sua pretensão de legitimidade na própria legitimidade da causa, no objetivo que a constituía. Era também este conteúdo que informava a representação que os atores construíam de suas práticas. Tal representação se prestava ao autoconsumo dos protagonistas da violência e funcionava como moeda de troca, através da qual se buscava ampliar sua legitimidade no conjunto da sociedade e desqualificar seus 'inimigos'. Tais configurações da violência não se extinguiram por completo, mas certamente cederam espaço a outros conteúdos. Por exemplo, o deslocamento de valor da categoria trabalho destrói identidades e produz o crescimento do individualismo ao mesmo tempo em que fabrica novas identidades coletivas, articuladas a uma pluralidade de perspectivas certamente mais complexas do que a polarização capital/trabalho, legitimadora de alguns sentidos que a violência assumia.

Essa mudança é igualmente sentida na reflexão desenvolvida por Wieviorka com relação a países da Europa ocidental: "O declínio do movimento operário e a perda do lugar central das relações de produção industriais tornam improváveis a idéia de uma ligação entre importantes violências sociais e a inserção de seus agentes num conflito estrutural de classe, no sentido habitual da expressão. Não é mais a luta contra a exploração, a sublevação contra um adversário que mantém com os atores uma relação de dominação, e sim a nãorelação social, a ausência de relação conflitual, a exclusão social, eventualmente carregada de desprezo cultural ou racial, que alimentam hoje em toda parte do mundo, inclusive na Europa ocidental, condutas amotinadoras ou uma violência social mais difusa, fruto da raiva e das frustrações" (Wieviorka, 1997, p. 7) O autor sinaliza, além disto, para o fato de a violência hoje não mais possuir legi- 
timidade social ou política enquanto forma de regulamentação social, inscrevendo-se como o não-social que invade o social.

Mesmo ao risco de generalizações precipitadas, pode-se dizer que as últimas manifestações contra o terrorismo na Europa sinalizam para a recusa de legitimidade à violência política.

Sob a perspectiva da esfera valorativa, algumas dentre as novas formas de manifestação da violência parecem ter esvaziado das práticas possíveis conteúdos de normatividade e de sentido; afirmam-se sobretudo como recurso de ação, mecanismo, meio. Se o social é múltiplo, também o são as diferentes lógicas de ação nele presentes. Nesta condição de recurso, a violência se insere em um rol de estratégias. Sua utilização não se vincula a nenhuma hierarquia valorativa; apenas é questão de eficácia ou oportunidade. É uma violência que se autonomiza face a prováveis sentidos de origem ou que já se constitui enquanto violência destituída de objeto.

Se tais violências se inserem enquanto produto no contexto das transformações em processo no mundo contemporâneo, elas se constituem, também, em fator de transformação do social na medida em que as interações resultantes da violência, mesmo ilegítimas, engendram seu próprio contexto. Os grupos sociais, atores desta violência, impõem formas de regulação a partir da própria lógica da violência. Os atores se criam nestes novos processos de interação, criando da mesma forma uma multiplicidade de novas identidades. Identidades que se constroem muito mais a partir de referências culturais do que econômicosociais. Como exemplo, tem-se a formação de identidades coletivas cujo apelo é racial, religioso, biológico, dentre outros. Face à pluralidade de valores e de configurações sociais resultantes dos processos de transformação social, os sentidos, as significações da violência são sempre mutantes.

Perceber a natureza deste novo na violência, identificar as novas lógicas de ação que incluem a violência como prática instrumentalizada, despolitizada, a natureza das interações sociais a elas subjacentes e os novos atores sociais que elas produzem é tarefa da análise sociológica.

Um componente importante desta tarefa, conforme aponta Wieviorka, é a necessidade de se perceber níveis ou instâncias de mediação entre mudanças sociais e fenômenos de violência: "Se há certamente uma ligação entre a violência e essas mudanças sociais, tal ligação não é automática e imediata, a violência deve ser concebida a partir dessas mediações. Ela não surge diretamente da mobilidade descendente, ou da crise; assim, os motins dos bairros difíceis da França ou da Inglaterra ou das grandes metrópoles americanas sobrevêm por ocasião de excessos policiais ou de decisões inadequadas da justiça, bem mais do que como um protesto contra o desemprego; a raiva e o ódio dos jovens exprimem-se certamente tendo por trás um cenário marcado por dificuldades sociais, mas correspondem acima de tudo a sentimentos fortes de injustiça e de não reconhecimento, de discriminação cultural e racial. O desemprego e a pobreza... não se traduzem imediatamente ou diretamente em violências sociais... mas sobretudo alimentam frustrações..." (Wieviorka, 1997). 
A citação acima introduz a reflexão a respeito de manifestações de violência ocorridas no Brasil envolvendo a violência policial - o episódio de Diadema sendo, sob este aspecto, exemplar - e as violências de jovens, membros dos estratos médios da sociedade, como vimos acontecer em Brasília ${ }^{1}$.

A pretensão do artigo não foi a de realizar estudos de caso. Assim a alusão às duas situações referidas deve ser entendida apenas como exemplo das reflexões desenvolvidas.

As duas situações mencionadas, ocorridas à mesma época, foram objeto de mobilização de diferentes esferas da sociedade. Fazendo um acompanhamento de noticiário de jornais, revistas e emissões de televisão, nos quinze dias que se seguiram aos acontecimentos, o que ressalta de comum é que ambos os casos produziram aquele sentimento do insuportável, do revoltante, aliado à reivindicação por punição, compatíveis com o que foi acima referido como o aguçamento da sensibilidade coletiva. A partir daí, pouco há em comum entre estes acontecimentos.

A violência de jovens, membros das camadas médias, poderia ser pensada, ao que tudo indica, como uma manifestação do que foi referido no início do texto como situações nas quais o(s) mesmo(s) ator(es) vivencia(m) processos de inclusão/exclusão. Jovens integrados na dimensão socioeconômica, participantes dos direitos que os definem como cidadãos, manifestam, pela violência, uma exclusão dos processos identitários. Os grupos ou gangues em que se inserem não parecem constituir uma expressão da construção de identidade, mas de um individualismo que apenas atua através do grupo. Mergulhados, mais do que inseridos, em um social carente de pontos fixos de referência, estes indivíduos expressam uma exclusão que não é social, é existencial. Excluídos do que seja a percepção de um sentido de vida, inviabilizam, nos termos weberianos (Weber, 1968), a percepção do sentido de morte. Amorteé (ou pode ser como no caso dos jovens de Brasília) uma brincadeira que deu errado. Não são monstros, praticam monstruosidades. Aqui, nem mesmo existe uma instrumentalização da violência porque não existe objetivo a atingir. Nem estratégias, pois não existem atores em luta contra um sistema, mas afirmação de força como recusa à negação do sujeito. A violência sem objeto, destituída de sentido pode, pela emoção, pelo jogo, se constituir em um fim em si mesmo, sendo indiferente se seres humanos são objetificados. Uma destruição que se transforma em autodestruição, uma necessidade de inclusão (afirmação como sujeito) que leva à exclusão, expressa em comportamentos de automarginalização.

A violência policial parece vinculada a outra ordem de sentidos. Produto de uma crise prolongada nos mecanismos de segurança, este tipo de violência transita nos limites tornados frágeis entre a violência legítima (exercício do monopólio do Estado) cujo agente é a autoridade policial e a violência ilegítima, enquanto desdobramento desta mesma autoridade. Fragilidade expressa na precariedade das condições materiais do agente policial, com desdobramentos em termos de uma igualmente precária inserção social, que o situa nos limites entre a integração formal do sujeito de direitos e a exclusão
${ }^{1}$ No primeiro caso, tratam-se de atos de violência praticados por policiais militares contra populares na Favela Naval em Diadema, São Paulo, no início de março de 1997. As agressões foram registradas em vídeo e exibidas pela televisão, no Brasil e no exterior. No outro episódio mencionado cinco jovens, sendo um menor, jogaram álcool e atearam fogo no índio Pataxó Galdino Jesus dos Santos, que dormia em um ponto de ônibus, queimando-o vivo e ocasionando sua morte. $\mathrm{O}$ fato aconteceu a 20 de abril, também de 1997, véspera da data que comemora o dia do índio no Brasil. 
de fato em termos da participação na sociedade de consumo, em termos da relação entre expectativa e possibilidades concretas de satisfação de suas demandas, sejam elas de natureza material (econômico-social) ou ideal (cultural, política). São indivíduos marginalmente situados na escala de prestígio social, mas que detêm, através do ato mesmo de intervenção policial, poder e autoridade, o que significa, no limite, poder sobre a vida e sobre a morte.

Também nesse caso, pode-se refletir nas conseqüências em termos do processo de constituição social de suas identidades, individuais e coletivas. Subjetividades reprimidas que põem em ação uma lógica ambígua, através da qual violência legítima e ilegítima se interpenetram num movimento onde a violência enquanto instrumento, mecanismo, estratégia, recurso exprime igualmente revoltas e raivas que a discriminação e a desvalorização social dessa categoria fazem vir à tona. Esses são contextos nos quais, para Wieviorka, a violência tem "a marca de uma subjetividade negada, arrebentada, esmagada, infeliz, frustrada... Deste ponto de vista, a violência é suscetível de emergir na interação ou no choque de subjetividades negadas ou destruídas, como se observa em determinados motins, onde o sentimento, por parte dos amotinados, de não serem reconhecidos remete os policiais à convicção simétrica de serem desvalorizados ou insultados por aqueles que ele deve reprimir"(Wieviorka, 1997, p. 37).

A imagem do barril de pólvora é pertinente: os noticiários estão repletos de situações recentes nas quais a repressão policial, utilizada para o restabelecimento da ordem, tomou ares de guerra civil, produzindo, como referido mais acima, uma violência que engendra seu próprio contexto.

O outro lado da mesma moeda revela-se quando a produção social da insegurança faz da violência uma representação quase onipresente e de seu corolário, a institucionalização da segurança privada, a solução para a questão. Quadro que beira a anomia quando esta última se efetiva através do que Paixão (1995, p. 514) chama, ao lado de outras possíveis modalidades, de os "grupos neovigilantes de venda privada de segurança pública".

Crise dos poderes públicos de produção de segurança pública e precariedade de vida material e simbólica dos agentes dessa segurança são ingredientes para a manifestação de uma simbiose público/privado, que tende a se constituir em fator de constrangimento para a consolidação de uma sociedade moderna, sempre que tal simbiose for sinônimo de captura do público pelo privado.

O caráter ensaístico deste texto impede afirmações de cunho conclusivo ou que se assumam como propostas, sugestões etc. Não invalida, no entanto, algumas considerações finais.

Tendo indicado no início do texto mudanças importantes na natureza da sociedade brasileira, fruto de transformações no contexto internacional, o texto discute, na segunda parte, os reflexos destas transformações nos sentidos sociais da violência. Assinalando, ao mesmo tempo, a impossibilidade de se estabelecer relações diretas entre esses fenômenos e a urgência da análise sociológica refletir em termos de mediações que tornem viável a compreensão dos novos sentidos da violência na sociedade brasileira, a partir de variá- 
veis que indiquem suas peculiaridade culturais.

As reflexões até aqui elaboradas caminham no sentido de apontar a natureza do espaço público como caminho viável para se pensar tais mediações. No que nisto pode haver de positivo e de negativo. A construção de um espaço público com graus crescentes de autonomia e de institucionalização poderá criar o espaço para consolidação de demandas mais universalistas face a interesses particularistas, espaço de participação da sociedade civil. Nos termos propostos por Wieviorka, de cujas reflexões nos apropriamos uma última vez em apoio à nossa argumentação: "Se a violência, mesmo não política, infra ou metapolítica, remete ao ponto central onde se situa a política, isso significa que ela surge e se desenvolve através das carências e dos limites do jogo político, e que ela pode também, se as condições políticas estiverem reunidas, regredir ou desaparecer em função de um tratamento institucional das demandas que ela vem traduzir"(Wieviorka, 1997, p. 38).

Assim, interpretando a argumentação do autor, pode-se supor que se a delimitação de um espaço público, diferenciado da ordem privada e da esfera estatal, é parte constituinte do refinamento da sensibilidade coletiva (que no caso brasileiro tem permitido nomear a violência como tal e exigir sua regressão), é também sua insuficiência que responde por muitos dos novos sentidos da violência na medida em que constrange as possibilidades de consolidação de canais de institucionalização da discussão, do debate e do conflito.

A multiplicidade valorativa e a fragmentação social em diferentes níveis, que a modernidade tem produzido, necessitam de espaços de manifestação das diferenças e do conflito, enquanto mecanismos de 'prevenção' contra a violência.

Recebido para publicação em setembro/1998

PORTO, Maria Stela Grossi. Violence between social inclusion and exclusion. Tempo Social; Rev. Sociol. USP. S. Paulo, 12(1): 187-200, May 2000.

ABSTRACT: This paper analyses the new meanings of violence in Brazil. It argues that they emerge due to changes in the nature of Brazilian society. These are included in the context of more widespread transformations that associate processes of globalization and fragmentation. The text also discusses new angles of analysis that lead to thinking about violence through a relationship between exclusion/inclusion seen, not as excluding and dichotomic forms but as categories which belong to the same dynamic process, in which social actors can alternatively experiment forms of inclusion/exclusion originating from fragmented, differentiated, plural social processes.

UNITERMS: urban violence, social inclusion, social exclusion, social change. 


\section{REFERÊNCIASBIBLIOGRÁFICAS}

Elias, Norbert. (1990) O processo civilizador: uma história dos costumes. Rio de Janeiro, Jorge Zahar.

FreIRE, Gilberto. (1963) Casa-grande \& senzala. Brasília, Editora da Universidade de Brasília.

Michaud, Y. (1978) Violence et politique. Paris, Gallimard.

PAIXÃo, Antônio Luiz. (1995) Crime, controle social e a cultura oficial da Sociologia. Sociologia e Estado, 10(2): 513-521, julho-dezembro.

Weber, M. (1968) Le savant e le politique. Paris, Plon.

Wieviorka, M. (1997) O novo paradigma da violência. Tempo Social, São Paulo, 9(1): 5-41, maio. 